PROCEEDINGS OF THE WORLD CONFERENCE ON OZONE THERAPY IN MEDICINE, DENTISTRY AND VETERINARY. ANCONA (ITALY). SEPTEMBER 22nd - 23rd - 24th, 2017

\title{
Adaptive hypothesis of system ozone therapy or why the ozone shifts always physiological and biochemical parameters of the organism towards the standard level? [abstract]
}

\section{Eugene Nazarov}

Scientific Department of Econika Biomedical Engineering, Odessa, Ukraine

\section{ABSTRACT}

\section{OPEN ACCESS}

\section{Citation}

Nazarov E. Adaptive hypothesis of system ozone therapy or why the ozone shifts always physiological and biochemical parameters of the organism towards the standard level? [abstract]. Proceedings of The World Conference on Ozone Therapy in Medicine, Dentistry and Veterinary. Ancona (Italy). September 22nd - 23rd - 24th , 2017. J Ozone Ther. 2019:3(4):47. doi: 10.7203/ jo3t.3.4.2019.15528

\section{Academic Editor}

Jose Baeza-Noci,

School of Medicine, Valencia

University, SPAIN

\section{Editor}

World Federation of Ozone Therapy, Bolgna, ITALY

\section{Received}

June 17, 2019

\section{Accepted}

December 08, 2019

Published

December 30, 2019

\section{Intellectual Property}

Eugene Nazarov.

This is an open access article distributed under the terms of the Creative Commons Attribution License (CC BY 4.0), which permits unrestricted use, distribution, and reproduction in any medium, provided the original author and source are credited.

\section{Author Information} ozoneinfo@yahoo.com
Introduction: The ozone as pharmacological factor could be characterized as a substance with an extremely broad range of physiological activity and an extremely high efficacy.

Another distinctive feature is an invariable normalizing effect on physiological and biochemical parameters of organism (higher values are decreased, reduced values are increased); this feature is uncommon for pharmacotherapy.

Under the adaptive hypothesis the ozone is a signal factor which initiates the transition of the adaptive system to one of certain states; a considerable part of ozone system effects (immunotropic, vasodilator, anti-inflammatory and others) result from the change of hormonal status of organism.

Material and Methods: For verification of this hypothesis we have evaluated the state of the organism adaptive system of 24 conditionally healthy volunteers at the age between 20 and 80 years.

Results: On basis of received data a mathematical model has been developed. It was established that this model prognosticates satisfactorily the patient's age under the data of leukoformula and / or psychosomatic testing. The soft $\mathrm{O} 3$ Navigator was used for state monitoring of patients suffering from deceases of various aetiology during of 85 courses of ozone therapy. All patients received a standard course of autohemotherapy major every two days. We have shown that the ozone therapy provokes a sharp and typical evolution of blood leukoformula.

Conclusions: On the basis of received data a new tactic of system ozone therapy is proposed. 